\title{
Organization of volunteers in the healthcare system and the type of services provided by them during the COVID-19 pandemic
}

\author{
PEYGHAM HEIDARPOOR ${ }^{1, F}$, MAHMOOD MANIATI 2, B, MARIA CHERAGHI 3, A, D, \\ ORCID ID: 0000-0002-6628-8786 \\ MARYAM BEHESHTINASAB ${ }^{4, B, E}$, POORANDOKHT AFSHARI \\ ORCID ID: 0000-0002-3383-9908
}

\author{
${ }^{1}$ Virtual School of Medical Education and Management, Shahid Beheshti University of Medical Sciences, Tehran, Iran \\ ${ }^{2}$ School of Medicine, Ahvaz Jundishapur University of Medical Sciences, Ahvaz, Iran \\ ${ }^{3}$ Department of Social Dentistry and Oral Health, School of Dentistry, Social Determinant of Health Research \\ Center, Ahvaz Jundishapur University of Medical Sciences, Ahvaz, Iran \\ ${ }^{4}$ School of Nursing and Midwifery, Ahvaz Jundishapur University of Medical Sciences, Ahvaz, Iran \\ ${ }^{5}$ Reproductive Health Promotion Research Center, Ahvaz Jundishapur University of Medical Sciences, Ahvaz, Iran
}

A - Study Design, B - Data Collection, C - Statistical Analysis, D - Data Interpretation, E - Manuscript Preparation, F - Literature Search, G - Funds Collection

Summary Background. In the event of accidents and disasters, the presence of volunteers, if not organized, can sometimes worsen the situation instead of improving it.

Objectives. This research was aimed at the ways of organizing volunteers in the healthcare system during the COVID-19 pandemic in the southwest of Iran.

Material and method. This questionnaire-based descriptive study was conducted on 140 volunteer health workers either active in providing services to COVID-19 patients or on the waiting list. The participants were selected using convenience sampling. They completed the information form, which was analyzed after collection using SPSS version 22.

Results. The 140 volunteers' mean age was 32.5 with a standard deviation of 7.5 . Of these volunteers, $62.1 \%$ had volunteered to serve since the first days of the outbreak. According to the participants of this study, the management of volunteers was spontaneous under the supervision of the official and state system, and the vast majority of them considered the official healthcare system's reception of volunteers as positive but saw the bureaucracy as a major obstacle to recruiting volunteers, especially nursing and midwifery graduates. Finally, the participants' motive for volunteering was found to be a sense of personal responsibility and human duty.

Conclusions. Proper planning, organization and management of volunteers in an epidemic situation should be taken into account by healthcare officials in order to receive the highest efficiency in times of crises such as the COVID-19 pandemic.

Key words: delivery of health care, volunteers, COVID-19, pandemics.

Heidarpoor P, Maniati M, Cheraghi M, Beheshtinasab M, Afshari P. Organization of volunteers in the healthcare system and the type of services provided by them during the COVID-19 pandemic. Fam Med Prim Care Rev 2021; 23(2): 169-173, doi: https://doi.org/10.5114/ fmpcr.2021.105909.

\section{Background}

Several cases of pneumonia reported in December 2019 in Wuhan, Hubei Province, China, now known as COVID-19 [1], caused a pandemic. Initially, a hospital in Washington state predicted that with the rising trend in the number of patients, there may not be enough ventilation equipment. In Michigan, the hospital system warned that the increased number of patients beyond hospital capacity could lead to only some patients selectively being provided full services [2]. In Iran, this situation has caused some medical universities to declare that they need the help of the public, especially professionals from medical and allied health sciences, nurses, operating room and anesthesia technicians, etc., for better performance, despite using all their power and capacity to solve this problem [3]. A closer look at the results of surveys around the world shows that if a natural disaster strikes a community, people feel the need to do something to help those affected by the situation. This is evidence of the dynamic attitude in society towards a natural disaster [4]. During Hurricane Katrina in the United States, for example, the
Red Cross alone recruited 50,000 volunteers. It is estimated that two million people helped during the 1985 Mexico City earthquake, though most of them had little information about the crisis, which can create challenges for relief services and recovery from a crisis [5]. The presence of local volunteers during an accident is particularly important, because they are often the first respondents and have the best chance of saving lives and providing protection in the hours and days immediately after a disaster [6].

The International Federation of Red Cross and the Red Crescent Society defines voluntary service as follows: "Voluntary services are services that volunteers perform voluntarily and not because of any social, economic and political factors imposed on them, and the purpose of which is to provide services to the vulnerable people of the society and not to gain material benefits" [7]. Volunteers are divided into two general categories of employed volunteers and spontaneous volunteers [8]. Another type of volunteer is the digital volunteer, whose role has rapidly become important in critical events [9]. These people use a variety of methods to provide information. Most studies suggest that this is done through Twitter services, but in 
Germany, $56 \%$ of this is through Facebook, while active Twitter use in this regard is only $6 \%[10]$.

The influx of people, from professional respondents to untrained people who all want to help in any way possible, to a place of disaster can be both an obstacle and a blessing [11]. While they are a great source of help, they also pose a difficult logistical problem, because there is no assurance of the number of these people and their availability and commitment to do work [12]. Volunteers can sometimes make things worse instead of better if they are not coordinated. Healthcare volunteers can enhance their efficiency by getting prepared prior to a disaster and thinking seriously about their ability to respond [13]. However, there is often no formal organization for hiring spontaneous volunteers [14]. The main reason for this may be the lack of training and limited experience of spontaneous volunteers, which can be dangerous [15].

Planning for an unplanned event is one of the most important new challenges in crisis management. Volunteers inherently represent a significant and flexible asset in response to disasters, but they will be problematic if there is no system to manage them properly [16]. The Community Emergency Response Team (CERT) program believes that planning, organizing, retraining, funding to support, maintaining activity and creating a network will help develop the CERT program [17]. Greece's experience in emergency management suggests that funding for spontaneous volunteer organizations, along with equipment provided by government agencies and other funding from national or international sources, is one of the factors involved in crisis management [18]. These reasons have led many managers to hesitate in hiring volunteer forces. The results of a content analysis showed that only a small number of officials mentioned the use of volunteers in their plans, and the perceptions expressed about the value of volunteers automatically affect how they make their plans [19].

However, with proper strategic planning to employ volunteer forces, the highest level of response to accidents can be achieved [20]. Extensive and rapid changes in the milieu of organizations' activities have provided the fundamentals for adopting various and appropriate measures and strategies. Non-governmental organizations are utilized in various ways around the world [21], but the main point is how to manage these institutions and spontaneous volunteers. In this study, the type of services provided by volunteers and the organization of these volunteers during the COVID-19 crisis were examined.

\section{Material and methods}

This study is a descriptive study in which the causes of voluntary service during the COVID-19 pandemic and the organization of volunteers by the relevant organizations were examined. The study population included volunteers who were already employed in centers not dedicated to COVID-19 patients and those who volunteered to work in COVID-19 hospitals. They include midwives, graduates of medical universities who are not employed at any specific organization, trained forces of the Red Crescent, as well as retirees from healthcare systems who volunteered to serve during the COVID-19 pandemic. The research sample size was selected to be 140 , and the participants were selected from the research population through convenience sampling.

First, according to the research objectives, a questionnaire was prepared and validated using the content validation method. To this aim, the initial information form was handed to 10 faculty members of Ahvaz University of Medical Sciences, and the following values were obtained: $\mathrm{CVR}=0.78$ and $\mathrm{CVI}=$ 0.81 . Reliability of the questionnaire was determined by 10 volunteers filling out the questionnaire and calculating Cranbach's alpha coefficient (0.82). All of these figures indicated that the questionnaire was appropriate to assess the research objec- tives. After verifying the questionnaire and identifying the qualified individuals to participate in the study, a questioner was briefed on the general purpose of research. The selected participants then completed the informed consent form, and the study questionnaire was given to them. Sampling continued until the size determined by the statistical consultant was reached.

After receiving the completed questionnaires, the data was coded and entered into the computer to be analyzed by SPSS statistical software version 22 .

This project was approved by the Ethics Committee (code: IR.AJUMS.REC.1399.107) of Ahvaz Jundishapur University of Medical Sciences.

\section{Results}

According to our analysis of the results from 140 volunteers, their average age was 32.5 with a standard deviation of 7.5. The youngest volunteer was 22 years old and the oldest was a 52 -year-old specialist (Table 1 ). Nearly two-thirds $(62.1 \%)$ of the participants stated that they volunteered to serve within the first days of the outbreak, while $26.4 \%$ indicated that they volunteered from the start of quarantine, and $11.4 \%$ reported that they had recently joined the volunteer forces. Regarding the type of service provided, $13.6 \%$ of the volunteers visited patients in hospitals, $16.4 \%$ managed those suspected of having COVID-19 in clinics and outpatient departments, 0.5\% provided specialized counseling to clients, $15.7 \%$ provided care for patients with COVID-19 in the hospital, $10 \%$ provided nursing services for patients at home after discharge from the hospital, $6.4 \%$ provided health services in health centers, $9.3 \%$ visited clients free of charge during the outbreak, $4.16 \%$ provided telephone counseling services, and $11 \%$ provided medical supplies, such as sanitizing gels for hands and surfaces, as well as masks.

Considering the position of virtual social media in today's life and their role in providing information about medical affairs and the possibility of providing consulting services through these media, we asked the participants about the applicability of these media in this regard, and $38.6 \%$ responded that the role of these media in providing services during this crisis is very useful, $52.1 \%$ considered it useful, and the rest as somewhat practical and useful. The most commonly used media were WhatsApp (53.6\%), Telegram (21.4\%) and other media (18.6\%), and $6.4 \%$ of the participants did not use any medium at all.

\begin{tabular}{|l|l|l|}
\hline \multicolumn{3}{|l|}{ Table 1. Demographic characteristics of volunteers } \\
\hline Percentage & Frequency & Volunteer characteristics \\
\hline 48.6 & 68 & A. Age \\
38.5 & 52 & $30-20$ \\
12.9 & 20 & $40-31$ \\
\hline & & $>41$ \\
27.9 & 39 & B. Education \\
11.4 & 16 & MD \\
11.4 & 16 & Specialist \\
20.7 & 29 & PHD \\
28.6 & 40 & MSc \\
\hline & & BSc \\
12.1 & 17 & C. Field of study \\
18.6 & 26 & Medical specialty and sub-specialty \\
2.9 & 4 & GP \\
5.7 & 8 & Dentist \\
22.1 & 31 & Pharmacist \\
20 & 28 & Nurse \\
18.6 & 26 & Midwife \\
\hline
\end{tabular}

In response to the question "What was the level of readiness of the system for receiving, organizing and employing volunteers?", $25.7 \%$ believed that the system lacked the necessary readiness, $50.7 \%$ considered the system unprepared, and $23.6 \%$ 


\begin{tabular}{|c|c|c|}
\hline Percentage & Frequency & Evaluation on the type of management plan \\
\hline $\begin{array}{l}24.3 \\
33.6 \\
9.3 \\
32.1\end{array}$ & $\begin{array}{l}34 \\
47 \\
13 \\
45\end{array}$ & $\begin{array}{l}\text { A. Planning for volunteers } \\
\text { Proper planning and organization } \\
\text { On the spot planning } \\
\text { Leaving planning to the volunteer } \\
\text { Lack of planning and organization }\end{array}$ \\
\hline $\begin{array}{l}6.4 \\
41.4 \\
8.6 \\
28.6 \\
10.7 \\
3.6\end{array}$ & $\begin{array}{l}9 \\
58 \\
12 \\
40 \\
15 \\
5\end{array}$ & $\begin{array}{l}\text { B. Official system's reception of volunteers } \\
\text { Adequate reception and assigning of space and facilities for service delivery } \\
\text { Adequate reception without assigning space and facilities } \\
\text { Assignment of space and facilities by the private sector for providing services } \\
\text { The bureaucratic system prevented the volunteers' applications for help } \\
\text { Despite the problems in the bureaucratic system, the volunteers' applications were accepted } \\
\text { Recording volunteers' details for emergencies }\end{array}$ \\
\hline $\begin{array}{l}32.1 \\
37.9 \\
12.1 \\
17.8\end{array}$ & $\begin{array}{l}45 \\
53 \\
17 \\
25\end{array}$ & $\begin{array}{l}\text { C. Management of volunteers } \\
\text { Official management by the state system } \\
\text { Spontaneous management under the supervision of the official state system of the Ministry of Health } \\
\text { Spontaneous management under the supervision of the Red Crescent } \\
\text { Spontaneous management of volunteers without the supervision of the official state system }\end{array}$ \\
\hline
\end{tabular}

described the system as fully prepared. We also examined the participants' assessments of the formal healthcare system in the organization and management of volunteers based on three subgroups of planning, receiving applications and management (Table 2). According to the majority of the participants, the planning for recruiting volunteers was done on the spot and in real time. As far as the management of volunteers was concerned, they described it as spontaneous management under the supervision of the official and governmental system. Most of the participants considered the official health and treatment system's reception of applications as good, but bureaucracy was seen as a major obstacle to the recruitment of volunteers, especially nursing and midwifery graduates.

In response to a question dedicated specifically to the problems of recruiting volunteers, the problems were listed as follows: no prior recognition of the professional qualifications of the volunteers $(55 \%)$, no recognition of the moral and social competence of the volunteer (13.6\%), cumbersome presence of these people and causing obstacles to the routine work of different units $(12.1 \%)$ and not having sufficient knowledge to provide standard requirements in some cases when it came to the provision of equipment (6.4\%). $12.9 \%$ did not know why they were not recruited.

The motive behind doing this voluntary service was our last question to the participants, and the most important and commonly mentioned motive was the sense of personal responsibility and human duty (Table 3 ).

Table 3. Participants' motive to provide voluntary services during the COVID-19 pandemic

\begin{tabular}{|c|c|c|}
\hline Percentage & Frequency & Motive \\
\hline 37.1 & 52 & $\begin{array}{l}\text { A sense of personal responsibility } \\
\text { and human duty }\end{array}$ \\
\hline 25.7 & 36 & Professional duty \\
\hline 11.4 & 16 & Religious duty and responsibility \\
\hline 10.7 & 15 & Social responsibility \\
\hline 1.4 & 2 & $\begin{array}{l}\text { Responsibility for family, relatives } \\
\text { and friends }\end{array}$ \\
\hline 6.4 & 9 & $\begin{array}{l}\text { Responding to people's needs } \\
\text { and preventing them from getting } \\
\text { confused }\end{array}$ \\
\hline 5 & 7 & Feeling of being useful \\
\hline 2.1 & 3 & $\begin{array}{l}\text { Belief in the return of one's good } \\
\text { deeds }\end{array}$ \\
\hline
\end{tabular}

\section{Discussion}

Humans have been and will continue to face various crises, and the presence of volunteers can be a great blessing in support of formal relief systems. The COVID-19 pandemic and the pressure caused by the influx of patients has struck a severe blow to even the strongest and most powerful healthcare systems in the world, and the need for voluntary help from specialists has been increasingly felt. In Iran, a number of hospitals were reserved for patients with COVID-19, and the treatment staff at these centers also treated patients not affected by coronavirus. Some even worked as midwives in the obstetrics and gynecology departments. This group volunteered to provide services at COVID-19 centers, and a number of other professionals and healthcare providers provided free advice to clients by dedicating their personal phone lines to this very purpose and are currently continuing their work. This is, of course, not a new activity. During the Black Saturday fire in 2009 in Victoria, Australia, for example, more than 22,000 people registered their interest in emergency organizations, yet only a part of these potential volunteers were recruited [5]. The role of these volunteers is very important, since their presence can reduce the feeling of isolation and abandonment in the victims of crisis-stricken areas. The quality and magnitude of the volunteers' response may be the key to minimizing the effects of accidents, maintaining order and increasing hope [6].

But what motivates people to risk their lives for the sake of helping others? In our study, the sense of personal responsibility and human duty, professional duty, religious duty and responsibility, social responsibility, responsibility towards family and friends, responding to people's needs and preventing their confusion, a feeling of being useful and believing in the return of good deeds were cited as reasons for voluntary action. In some studies, a sense of personal responsibility has been cited as the main motive for voluntary assistance [4]. Babakhani et al. cited a set of factors influencing participation in times of crisis, including social trust, economic class and social isolation, with social trust and social isolation being the most influential factors in people's willingness to voluntarily participate in times of crisis [22]. Sauer et al. see more structured efforts as a very effective, important and safe way to utilize spontaneous volunteers in responding to crisis [15]. According to Farajollah et al., the identification of effective factors that attract volunteers, such as incentives, technical means of communication and advertis- 
ing, information tools, attention to human relations and factors related to their maintenance, organizational culture, human resource management, participation and teamwork, management and leadership tasks and motivation are the main factors in the organization of volunteers [23].

One of the issues during crises, such as the COVID-19 pandemic addressed in this study, is how to manage volunteers. According to our results, on the spot planning and even leaving the planning to be done by the volunteer was mentioned as the most common form of planning. On the other hand, most of the participants in this study mentioned spontaneous management under the supervision of official or unofficial government authorities as the way these forces were organized. Different groups also had mixed opinions about the reception and planning of the system with regard to volunteers. These mixed opinions are likely to be due to the difference between the required fields of study and the difference between the units requesting the relevant service. In areas related to physicians, especially specialists, the system seems to be more prepared and more welcoming and organized. Adib believes that a large part of crisis management is related to the management of volunteers (including rescuers, doctors, nurses, etc.). Attraction, organization and maintenance of volunteers and their recruitment should be based on the type of skills and expertise, as well as the needs during a crisis. Obviously, determining the existing needs and priorities is of paramount importance in creating appropriate interactions and institutionalizing management at organizational and operational levels [20]. Planning and training are very important for optimal response to emergencies. If managers take a few simple steps to predict future crises, healthcare providers can be identified and recruited more immediately in a crisis [13]. Twigg and Mosel also see self-organizing as a common feature of urban disasters. This includes search and rescue, transportation and distribution of relief supplies and provision of food and drink for the victims and emergency workers. However, informal actors are rarely incorporated into formal disaster and humanitarian planning [14]. According to our results, the most important reasons for the non-employment of the volunteers participating in this study were the lack of prior familiarity with their professional, moral and social competence and their cumbersome presence, creating an obstacle to routine work in the division of volunteers. The Red Crescent divides these volunteers into two major groups: volunteers with the necessary skills to respond to unique needs during a crisis who are recruited by the accident command system for assistance; spontaneous volunteers who do not have their own resources and are not specifically trained, but they actively seek to provide help [8]. Merchant et al. believe that the presence of volunteers, if not coordinated, can sometimes make matters worse instead of better [13]. According to Barraket et al., only some potential volunteers are used in accidents and crises, because most of them have little information about the crisis, and they can create challenges for relief and recovery services [5].

The use of the Internet has become an inevitable part of social life, and it is not surprising to see its presence in volunteers' provision of services. This form of service delivery is called digital volunteering, and although it is undoubtedly valuable, it can have both positive and negative consequences. Sometimes activities in hazardous areas can complicate matters and increase the risk of emergency services [10]. In this study, more than $80 \%$ of people used social media in their work, and the most commonly used medium was WhatsApp followed by Telegram. The role of Internet surveillance tools in the early detection of COVID-19 and other epidemic diseases, including influenza, H1N1, dengue fever, Zika measles and MERS, has already been reported [24]. Officials in Vietnam stated that despite their proximity to China, the proper use of social media to scan and collect official COVID-19 media news between January and April 4 helped them control the disease [25].

The question that is posed at this juncture is: How can governments thoughtfully avail themselves of the help of volunteers given their vital role in providing timely assistance in high-risk situations? According to the results of the present study, one of the most important steps to be taken by all official systems involved in providing services in times of crisis is training a group of volunteers and even educating the public about individual protection tips in the event of a crisis. This requires the provision of equipment and funding for volunteers [18], as well as careful planning [16]. In similar cases, groups of able-bodied retirees and healthcare graduates who are not officially employed anywhere can be integrated at a national or even a global level in order to provide assistance and education, whether virtually or in person, in the event of any catastrophe that might occur every few years. By doing this, they will be able to play a decisive role during crises.

\section{Conclusions}

Proper planning, organization and management of volunteers in epidemic conditions should be taken into account by the authorities of healthcare systems in order to achieve maximum efficiency in crises such as the COVID-19 pandemic.

Acknowledgements. The authors are grateful to the volunteers serving COVID-19 patients for completing the questionnaire of this study.

Source of funding: This study was funded by Ahvaz Jundishapur University of Medical Sciences, Ahvaz, Iran. Conflicts of interest: The authors declare no conflicts of interest.

\section{References}

1. Arabi YM, Murthy S, Webb S. COVID-19: a novel coronavirus and a novel challenge for critical care. Intensive Care Med 2020; 46(5): 833-836, doi: 10.1007/s00134-020-05955-1.

2. Baker M, Fink S. At the Top of the COVID-19 Curve, how do hospitals decide who gets treatment? (cited 31.03.2020). Available from URL: https://www.nytimes.com/2020/03/31/us/coronavirus-covid-triage-rationing-ventilators.

3. Jadidi R. Jihadi Struggle with Corona/Helping people's volunteers to the health system (cited 31.03.2020). Available from URL: https:// www.yjc.ir/fa/news/7268184

4. Michel LM. Personal responsibility and volunteering after a natural disaster: the case of hurricane Katrina. Sociological Spectrum 2007; 27(6): 633-652, doi: 10.1080/02732170701533855.

5. Barraket J, Keast R, Newton CJ. et al. Spontaneous volunteering during natural disasters. Brisbane: Queensland University of Technology; 2013.

6. Barnett R, Flint CG. Community volunteers: the front line of disaster response. The Journal of Volunteer Administration 2005; 23: 52-56.

7. Seyed Mahmoud Reza N. Voluntary service training (cited 10.03.2007). Available from URL: http://bashardustan.blogfa.com/post/8.

8. Fernandez LS. Volunteer management system design and analysis for disaster response and recovery [dissertation]. The School of Engineering and Applied Science of The George Washington University; 2007. 
9. Cobb C, McCarthy T, Perkins A, et al. Designing for the deluge: understanding \& supporting the distributed, collaborative work of crisis volunteers. In: Fussell S, Lutters W. CSCW '14: Proceedings of the 17th ACM conference on Computer supported cooperative work \& social computing. New York: United Association for Computing Machinery States; 2014: 888-899, doi: 10.1145/2531602.2531712.

10. Reuter C, Ludwig T, Kaufhold MA, et al. XHELP: Design of a Cross-Platform Social-Media Application to Support Volunteer Moderators in Disasters. In: Proceedings of the 33rd Annual ACM Conference on Human Factors in Computing Systems. 2015: 4093-4102, doi: 10.1145/2702123.2702171.

11. Barsky LE, Trainor JE, Torres MR, et al. Managing volunteers: FEMA's Urban Search and Rescue programme and interactions with unaffiliated responders in disaster response. Disasters 2007; 31(4): 495-507.

12. Mayorga ME, Lodree EJ, Wolczynski J. The optimal assignment of spontaneous volunteers. J Oper Res Soc 2017; 68(9): 1106-1116, doi: 10.1057/s41274-017-0219-2

13. Merchant RM, Leigh JE, Lurie N. Health care volunteers and disaster response - first, be prepared. N Engl J Med 2010; 362: 872-873, doi: 10.1056/NEJMp1001737.

14. Twigg J, Mosel I. Emergent groups and spontaneous volunteers in urban disaster response. Environ Urban 2017; 29(2): 443-458, doi: $10.1177 / 0956247817721413$.

15. Sauer LM, Catlett C, Tosatto R, et al. The utility of and risks associated with the use of spontaneous volunteers in disaster response: a survey. Disaster Medicine and Public Health Preparedness 2014; 8(1): 65-69.

16. Fernandez L, Barbera J, Dorp J van. Strategies for managing volunteers during incident response a systems approach. Homeland Security Affairs 2006; 2. Available from URL: https://www.hsaj.org/articles/684.

17. Flint CG, Stevenson J. Building community disaster preparedness with volunteers: community emergency response teams in Illinois. Natural Hazards Review 2010; 11(3), doi: 10.1061/(ASCE)NH.1527-6996.0000014.

18. Nivolianitou Z, Synodinou B. Towards emergency management of natural disasters and critical accidents: the Greek experience. J Environ Manage 2011; 92(10): 2657-2665, doi: 10.1016/j.jenvman.2011.06.003.

19. Rivera JD, Wood ZD. "Disaster relief volunteerism: Evaluating cities' planning for the usage and anagement of spontaneous volunteers". J Environ Manage 2016, 14(2): 127-138, doi: 10.5055/jem.2016.0279.

20. Mostafa A. Calling and organizing volunteer relief, health and medical forces in crisis. Third International Congress on Health Medication \& Crisis Management in Disasters. Tehran, January 2007. Available from URL: https://www.en.symposia.ir/ICHMCM03.

21. Pooladi A, Shahri R, Afsharpour S, et al. Investigation of effective factors in attracting and maintaining volunteer, youth and relief groups of Bushehr Red Crescent Society. Journal of Rescue and Relief Fifth 2013; 1: 31-39.

22. Babakhani F, Nasab MY, Nouri M. Important influential factors on people's tendency for voluntary participation during crisis. JEM 2014; 2(2): 5-13.

23. Farajollah R, Shahram A, Nahid SN. Identify effective factors to attract public volunteer groups for giving voluntarily services in Red Crescent society. Scientific Journal of Rescue Relief 2009; 1(2): 39-53.

24. Cuilian L, Jia CJ, Xueyu C, et al. Retrospective analysis of the possibility of predicting the COVID-19 outbreak from Internet searches and social media data, China, 2020. Euro Surveill 2020; 25(10): 2000199, doi: 10.2807/1560-7917.

25. La V-P, Pham T-H, Ho MT, et al. Policy response, social media and science journalism for the sustainability of the public health system amid COVID-19 outbreak: the Vietnam lessons. SocArXiv 2020, doi: 10.31219/osf.io/cfw8x.

Tables: 3

Figures: 0

References: 25

Received: 12.06 .2020

Reviewed: 29.06 .2020

Accepted: 17.01 .2021

Address for correspondence:

Poorandokht Afshari, PhD

Reproductive Health Promotion Research Center

Ahvaz Jundishapur University of Medical Sciences

Ahvaz

Iran

Tel.: +98 9166464984

E-mail: poafshari@gmail.com 